\title{
Lack of association of ACE2 G8790A gene mutation with essential hypertension in the Chinese population: a meta-analysis involving 5260 subjects
}

\author{
Yan-yan Li* \\ Department of Geriatrics, First Affiliated Hospital of Nanjing Medical University, Nanjing, China
}

\section{Edited by:}

Mariappan Muthuchamy, Texas A\&M

Health Science Center, USA

Reviewed by:

Ryuichi Morishita, Osaka University, Japan

Scott Earley, Colorado State

University, USA

Xin Wu, Texas A\&M Health Science

Center, USA

\section{*Correspondence:}

Yan-yan Li, Department of Geriatrics, First Affiliated Hospital of Nanjing

Medical University, Nanjing 210029,

China.

e-mail: lyynjmu123@126.com

\begin{abstract}
Background: The angiotensin converting enzyme 2 (ACE2) G8790A gene polymorphism has been associated with the susceptibility to essential hypertension $(E H)$, but the results are disputable. Objective and Methods: To investigate the relationship between the ACE2 G8790A gene polymorphism and EH, eight separate studies with 5260 subjects were meta-analyzed. The pooled odds ratio (OR) and its corresponding $95 \%$ confidence interval (CI) were calculated by a random effect model. Results: In the ACE2 G8790A gene polymorphism and $\mathrm{EH}$ meta-analysis in a Chinese population, no significant association was found between the ACE2 G8790A gene polymorphism and EH (OR: 1.03, 95\% Cl: 0.87$1.21, P=0.76)$. In the stratified analysis by gender, no significant risk was found among males (OR: $1.06,95 \% \mathrm{Cl}: 0.82-1.36, P=0.66$ ) or females (OR: $0.98,95 \% \mathrm{Cl}: 0.77-1.24$, $P=0.85)$. Under a dominant model of inheritance in the female subgroup, the pooled OR for the GG/GA + AA value was 1.01 (95\% Cl: $0.82-1.25, P=0.92)$. Under a recessive model of inheritance in the female subgroup, the pooled OR for the AA/AG + GG value was 0.93 (95\% Cl: $0.50-1.73, P=0.83$ ). Conclusion: The current meta-analysis suggested that the ACE2 G8790A gene polymorphism might not be related to the increased EH risk in the Chinese population.
\end{abstract}

Keywords: angiotensin converting enzyme 2, gene polymorphism, G8790A, hypertension, meta-analysis

\section{INTRODUCTION}

The gene polymorphism of angiotensin converting enzyme 2 (ACE2) has been associated with the pathogenesis of essential hypertension (EH). ACE2, a homolog of $A C E$ discovered by Donoghue et al. (2000) and Tipnis et al. (2000), has a catalytic domain $42 \%$ similar with that of ACE. ACE2 is mainly expressed in the kidney, but is also found in the heart, testes, blood vessels, lungs, brain, nose, mouth, gastrointestinal tissues, and so on. In contrast to $A C E, A C E 2$ is not obviously expressed in any of these tissues, but is mostly expressed in endothelial cells. ACE2 is located in the Xp22 chromosome with 18 exons. ACE2 hydrolyzes angiotensin (Ang) I and generates Ang 1-9. Ang 1-9 is resolved into Ang 1-7, whose physiological activities are contrary to Ang II. Ang 1-7 can relax vessels, decrease the blood pressure, as well as inhibit the proliferation of cardiac myocytes, myocardium fibroblasts, and vascular smooth muscle cells. Hence, ACE2 and ACE exhibit mutual antagonism. ACE2 is supposed to demonstrate a protective function in the regulation of heart and blood pressures. Consequently, ACE2 may become a new treatment target for cardiovascular diseases.

Angiotensin converting enzyme 2 gene, located in $\mathrm{X}$ chromosome, spans $\sim 2.4 \mathrm{~kb}$ and contains 18 exons. The G8790A polymorphism was at fourth base in the third intron adjacent to exon. The 8790th base guanine $(G)$ was substituted by adenine $(A)$ which resulted in the mRNA montage changes and ACE2 gene expression.

The association of the ACE2 G8790A gene polymorphism with $\mathrm{EH}$ significantly differed among various ethnicities. Benjafield et al. (2004) have found no association between the ACE2 G8790A gene polymorphism and $\mathrm{EH}$ in Australian individuals by a polymerase chain reaction-restriction fragment length polymorphism analysis (Benjafield et al., 2004). Zhong et al. (2006) have found that females and individuals carrying only the $\mathrm{G}$ allele had significantly higher risks for increased diastolic blood pressure (DBP). The ACE2 G8790A polymorphism is also concluded to be associated with hypertension in Han-Chinese patients with metabolic syndromes (Zhong et al., 2006). Jiang et al. (2010) found that the ACE2 G8790A polymorphism might be associated with EH. They reported that male populations with $\mathrm{G}$ allele and female population with GG genotype had higher risk of EH in China (Jiang et al., 2010). However, Si et al. (2009) reported that the A allele increased the EH risk only in the male Chinese population. They found no significant association of ACE2 G8790A gene polymorphism and EH in the female Chinese population. Zhou and Yang (2009) performed a meta-analysis on the ACE2 G8790A polymorphism with Chinese Han EH and they concluded that ACE2 G8790A polymorphism might not be genetic risk factor for $\mathrm{EH}$ in a Chinese Han population. In contrast, Lu et al. (2012) also conducted a similar meta-analysis and they found that ACE2 G8790A polymorphism was probably a genetic risk factor for $\mathrm{EH}$ across different ethnic populations in female subjects and in Han-Chinese male subjects.

The present meta-analysis, which involved 5260 participants, was performed to obtain a more precise and comprehensive estimation of the association between the ACE2 G8790A gene polymorphism and $\mathrm{EH}$ in the Chinese population. 


\section{MATERIALS AND METHODS \\ PUBLICATION SEARCH AND INCLUSION CRITERIA}

The electronic databases PubMed, Embase, Web of Science, China Biological Medicine Database, and China National Knowledge Infrastructure were searched in the current meta-analysis using the medical subject heading "hypertension," "ACE2," and "gene polymorphism.” The last research was performed on July 23, 2012. The range of publication years was from 2005 to 2010.

The inclusion criteria were as follow: (a) evaluation of the association between the ACE2 G8790A gene polymorphism and $\mathrm{EH}$; and (b) the $\mathrm{EH}$ diagnosis was in line with the $1999 \mathrm{EH}$ diagnosis criteria of the World Health Organization as systolic blood pressure (SBP) $\geq 140 \mathrm{mmHg}$, DBP $\geq 90 \mathrm{mmHg}$. Secondary hypertension was not included in the present investigation.

\section{DATA EXTRACTION}

Data were collected according to a standard protocol. Repeated publications, those that violate any inclusion criterion, and/or those deviating from the Hardy-Weinberg equilibrium (HWE) were excluded. If different articles conveyed the same results, the results were considered only once in the current meta-analysis. The information extracted from literature included the name of the first author, year of publication, region, number of genotypes, total number of cases, and controls listed in Tables S1 and S2 in
Supplementary Material. Given that ACE2 is located in the X chromosome, the meta-analysis was classified into male and female subgroups.

\section{STATISTICAL METHODS}

The strength of association between the ACE2 G8790A gene polymorphism and $\mathrm{EH}$ was assessed by the odds ratio (OR) corresponding to a $95 \%$ confidence interval (CI). The chi-squarebased $Q$-test was used to check the heterogeneity assumption (significance set at $P<0.05$; Cochran, 1968). Upon determination of heterogeneity among studies, the random-effects model was used to estimate the pooled OR by the DerSimonian and Laird method (DerSimonian and Laird, 1986). Otherwise, the pooled OR was estimated using the fixed-effects model (the Mantel-Haenszel method; Mantel and Haenszel, 1959). $I^{2}$ was used to assess the heterogeneity. The lower was the $I^{2}$, the smaller was the heterogeneity. Fisher's exact test was used to assess the HWE (significance set at $P<0.05$ ). The potential publication bias was estimated by the funnel plot. Egger et al.'s (1997) linear regression test of the natural logarithm scale of the OR (significance set at $P<0.05$ ) was used to assess the funnel plot asymmetry. The STATA 10.0 software (StataCorp, College Station, TX, USA) was used to perform all statistical analyses.

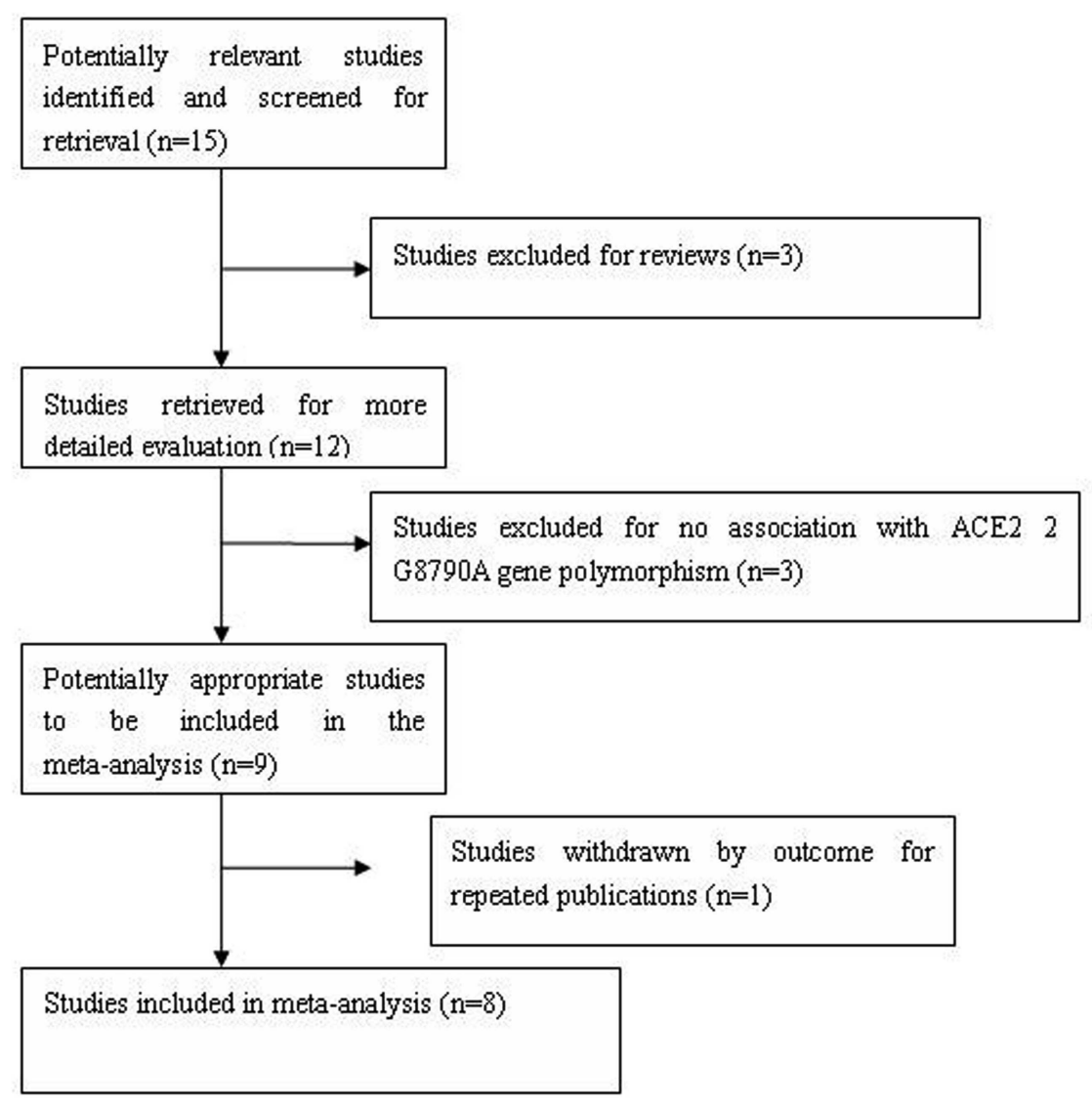

FIGURE 1 | Flow diagram of articles selection process for ACE2 G8790A gene polymorphism and EH risk meta-analysis. 


\section{RESULTS \\ STUDY CHARACTERISTICS AND META-ANALYSIS RESULTS}

A total of 15 papers were retrieved by the literature search, and eight of the papers fitted the study selection criteria. Of the seven excluded studies, three papers were reviews, three had nothing about the ACE 2 G8790A gene polymorphism, and one was a repeated publication (Zhang et al., 2008). In the female subgroup, four papers deviating from the HWE were excluded (Liu et al., 2005; Niu et al., 2007; Si et al., 2009; Zhang et al., 2010; Figure 1). In total, the data from the eight studies were gathered from 3090 men and 2170 women from three ethnicities. There were 2769 $\mathrm{EH}$ patients and 2491 controls. In the male subgroup, there were $1670 \mathrm{EH}$ patients and 1420 controls. In the female subgroup, there were $1099 \mathrm{EH}$ patients and 1071 controls. The OR values differed among the eight studies, and some of which approved that the A allele of G8790A increased the EH risk. However, the results of other studies were unclear and had to be integrated to reach a valuable conclusion. The three ethnicities included Han, Dongxiang and Li (Tables S1 and S2 in Supplementary Material; Liu et al., 2005; Hang et al., 2006; Yi et al., 2006; Fan et al., 2007; Niu et al., 2007; Si et al., 2009; Jiang et al., 2010; Zhang et al., 2010).

In the present ACE2 G8790A gene polymorphism and $\mathrm{EH}$ meta-analysis, under an allelic genetic model of inheritance, the distribution of the A allelic frequency was 0.496 for the $\mathrm{EH}$ group and 0.489 for the control. Figure 2 shows the summary OR of the distribution of the A allelic frequency, which was 1.03 (95\% CI:
0.87-1.21) by the random effects model. The heterogeneity comparisons significantly differed $\left(P=0.003, I^{2}=61.0 \%\right)$, but the EH and control groups did not $(P=0.76$; Table 1; Figure 2).

The summary OR of the distribution frequency of the A allele in the male subgroup was 1.06 (95\% CI: 0.82-1.36), as shown in Figure 2. In this subgroup, the distribution of the A allelic frequency was 0.469 for the $\mathrm{EH}$ group and 0.449 for the control. The heterogeneity among the eight studies significantly differed $\left(P=0.01, I^{2}=61.0 \%\right)$, but the $\mathrm{EH}$ and control groups did not $(P=0.66$; Table 1; Figure 2).

The summary OR of the distribution frequency of the A allele in the female subgroup was 0.98 (95\% CI: $0.77-1.24$ ), as shown in Figure 2. In this subgroup, the distribution of the A allelic frequency was 0.516 for the EH group and 0.516 for the control. The heterogeneity among the four studies also significantly differed $\left(P=0.02, I^{2}=69.2 \%\right)$, but the $\mathrm{EH}$ and control groups did not $(P=0.85$; Table 1; Figure 2).

Under a dominant model of inheritance in the female subgroup, the GG/GA + AA value was 0.317 for the EH group and 0.314 for the control. The pooled OR for the GG/GA + AA value was 1.01 $\left(95 \%\right.$ CI: $\left.0.82-1.25, P_{\text {heterogeneity }}=0.11, I^{2}=50.7 \%\right)$. The association between the ACE2 G8790A gene polymorphism and $\mathrm{EH}$ in the women was not significant $(P=0.92$; Figure 3; Table 1).

Under a recessive model of inheritance in the female subgroup, the $\mathrm{AA} / \mathrm{AG}+\mathrm{GG}$ value was 0.375 for the $\mathrm{EH}$ group and 0.373 for the control. The pooled OR for the AA/AG + GG value

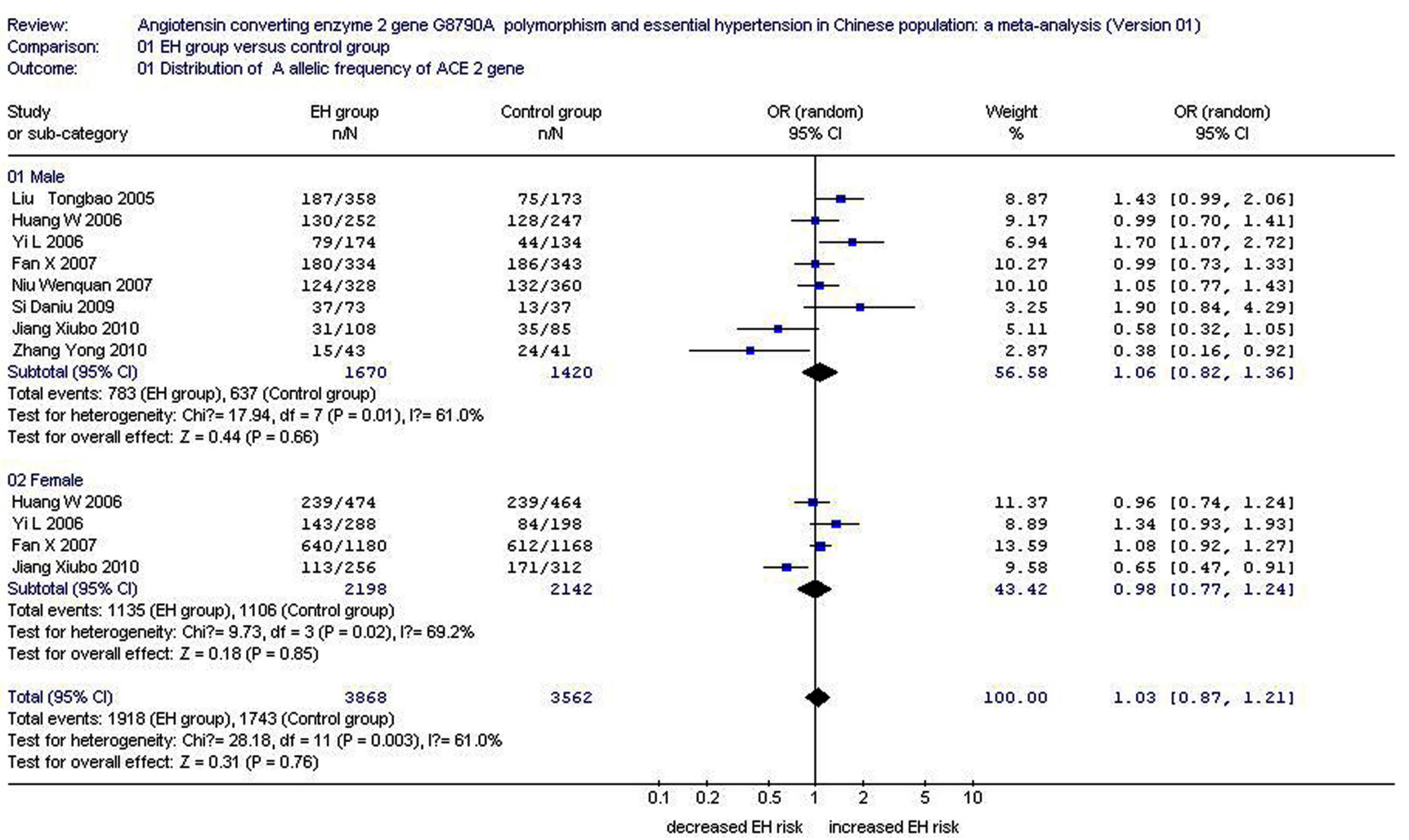

FIGURE 2 | Forest plot of EH associated with ACE2 G8790A gene polymorphism under an allelic genetic model stratified by gender (distribution of A allelic frequency of ACE2 gene). 
was 0.93 (95\% CI: $\left.0.50-1.73, P_{\text {heterogeneity }}=0.0001, I^{2}=85.5 \%\right)$. There was no significant association between the ACE2 G8790A gene polymorphism and $\mathrm{EH}$ in the women $(P=0.83$; Figure 4; Table 1).

Meta-regression was conducted to explore the potential sources of heterogeneity in the male subgroup under the allelic genetic model of inheritance. The confounding factors included the publication year, study region, ethnicity, G genotype number of $\mathrm{EH}$ group sample size (G1), and G genotype number of control group sample size (G0). All these confounding factors could explain the heterogeneity $(P<0.05)$, but publication year was the most important $(P=0.017$; Table 2$)$.

In the subsection analysis stratified by the publication year, Subsection 1 was defined as publication year ranging from 2005 to 2007. Studies with publication year ranging from 2009 to 2010 were defined as Subsection 2. In Subsection one of five studies, the pooled OR was 1.16 (95\% CI: $0.95-1.40, P_{\text {heterogeneity }}=0.20$, $I^{2}=33.8 \%$ ). In Subsection 2 of three studies, the pooled OR was 0.74 (95\% CI: $\left.0.31-1.79, P_{\text {heterogeneity }}=0.02, I^{2}=74.9 \%\right)$. The subsection analysis indicated that the heterogeneity in Subsection 2 was higher than that in Subsection 1. Therefore, studies on Subsection 2 need further improvement (Table 3; Figure 5).

Table 1 | Summary of meta-analysis of association of ACE2 G8790A gene polymorphism and EH risk in the Chinese population.

\begin{tabular}{llll}
\hline Gender & Pooled OR (95\% Cl) & $\boldsymbol{Z}(\boldsymbol{P})$ & $\boldsymbol{I}^{\mathbf{2}(\%)}$ \\
\hline Allelic genetic model & $1.03(0.87-1.21)$ & $0.31(P=0.76)$ & 61.0 \\
$\quad$ Male subgroup & $1.06(0.82-1.36)$ & $0.44(P=0.66)$ & 61.0 \\
$\quad$ Female subgroup & $0.98(0.77-1.24)$ & $0.18(P=0.85)$ & 69.2 \\
Dominant genetic & $1.01(0.82-1.25)$ & $0.10(P=0.92)$ & 50.7 \\
model for female & & & \\
Recessive genetic & $0.93(0.501-1.73)$ & $0.22(P=0.83)$ & 85.5 \\
model for female & & &
\end{tabular}

$\mathrm{Cl}$, confidence interval; OR, odds ratio; Allelic genetic model: distribution of $A$ allelic frequency of ACE2 gene; Dominant genetic model: GG/GA $+A A$; Recessive genetic model: $A A / G A+G G$.

\section{BIAS DIAGNOSTICS}

No visual evidence of publication bias was found from the funnel plot (Figure 6). There was also no significant difference in the Egger's test under the allelic genetic model, which implied that the publication bias was low in the current meta-analysis $(P=0.658$, $T=0.46)$.

\section{DISCUSSION}

Essential hypertension is a complex disease caused by a combination of genetic and environmental factors. Crackower et al. (2002) have found that although the gene knockout of ACE2 does not affect blood pressure regulation, the serum Ang II level significantly increases. The cardiovascular and renal effects of Ang II are the most important long-term blood pressure regulation mechanisms. They have also found that ACE2 knockout mice exhibit the cardiac abnormalities similar with cardiac stunning in humans.

The G8790A gene polymorphism of ACE2 is the restriction enzyme cutting site located on the fourth base of the third intron. The code is ranked as rs2285666 in the United States Biotechnology Information Center. mRNA and protein expression levels change in cardiovascular diseases and diabetes mellitus (DM; RibeiroOliveira et al., 2008). Hence, the G8790A gene polymorphism may participate in the onset of such illnesses as hypertension, cardiac dysfunction, and DM. The G8790A gene polymorphism is situated in the intron adjoined to the extron, suggesting that this locus could alter mRNA alternate splicing and affect ACE2 gene expression. The latter led to changes in the serum content of Ang 1-7 that inhibited vasoconstriction and cell proliferation (Kramkowski et al., 2006).

Given the location of the ACE2 gene in $\mathrm{X}$ chromosomes, the association of the G8790A gene polymorphism and $\mathrm{EH}$ was classified and analyzed according to gender. In the present metaanalysis, under the premise that age and gender factors were controlled, no significant association was found between the ACE2 G8790A gene polymorphism and $\mathrm{EH}$ under allelic, dominant, and recessive genetic models. There was no significant difference between the $\mathrm{EH}$ and control groups in either male or female subgroups. The current meta-analysis suggested that the A allele of

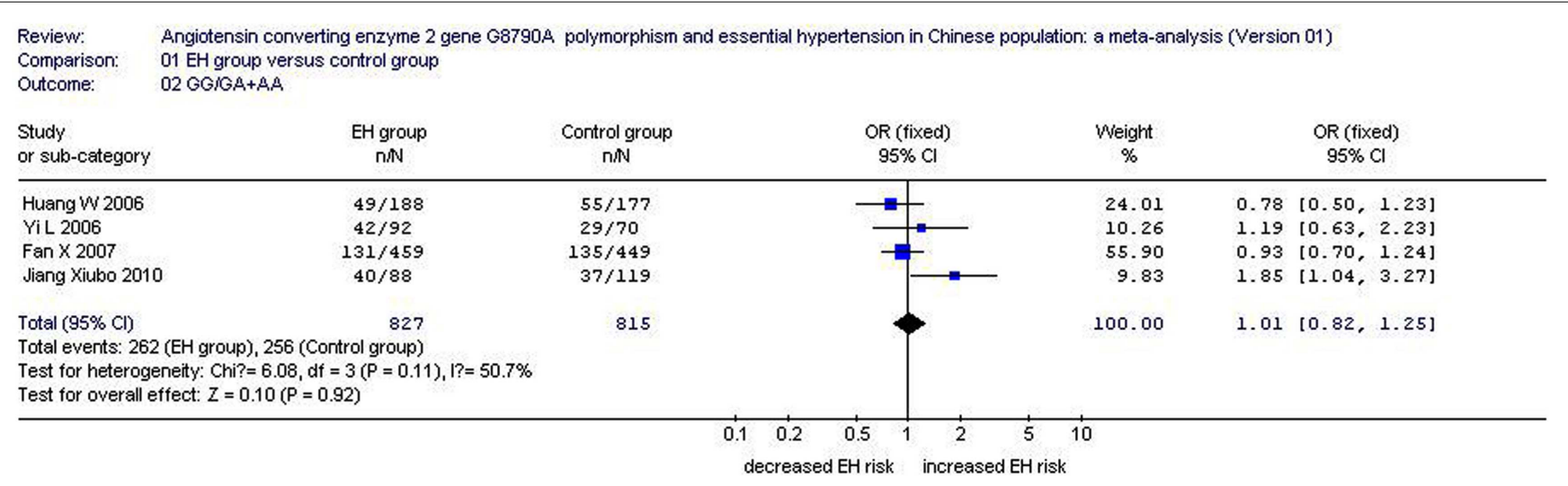

FIGURE 3 | Forest plot of the dominant genetic model of EH associated with ACE2 G8790A gene polymorphism in female population (GG/GA + AA value of angiotensin converting enzyme 2 gene). 


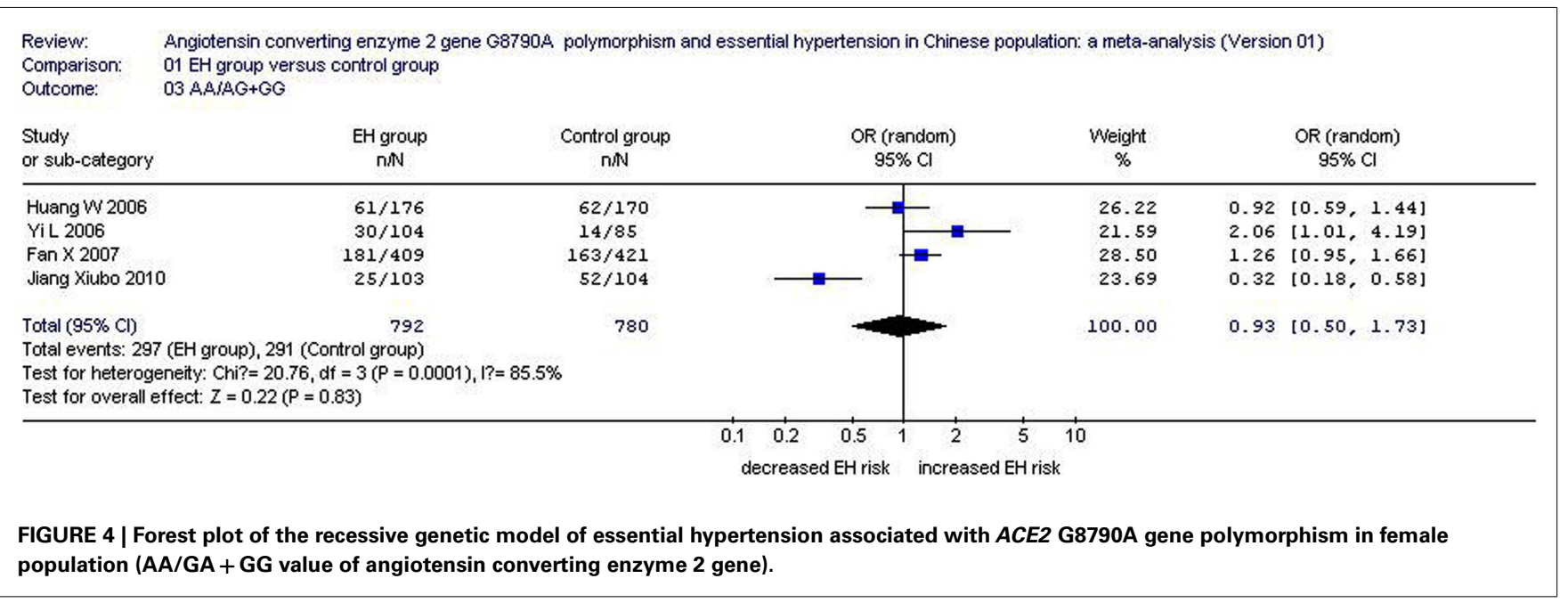

Table 2 |The meta-regression results among eight studies in the male subgroup under the allelic genetic model.

\begin{tabular}{lccccc}
\hline Item & Coefficient & Standard error & $\boldsymbol{T}$ value & $\boldsymbol{P}$ value & 95\% Confidence interval \\
\hline Weight & -0.1845581 & 0.014793 & -12.48 & 0.051 & -0.3725206 to 0.0034044 \\
Publication year & -0.5106332 & 0.0132544 & -38.53 & $0.017^{*}$ & -0.6790462 to -0.3422202 \\
Region & -0.8178791 & 0.0265906 & -30.76 & $0.021^{*}$ & -1.155745 to -0.480013 \\
G genotype number of EH group size & 0.0111473 & 0.0005284 & 21.10 & $0.030^{*}$ & 0.0044336 to 0.017861 \\
Ethnicity & -0.3915033 & 0.0197832 & -19.79 & $0.032^{*}$ & -0.6428729 to -0.1401337 \\
G genotype number of control group size & -0.0156601 & 0.0007113 & -22.02 & $0.029^{*}$ & -0.0246984 to -0.0066219 \\
Cons & 1028.613 & 26.69087 & 38.54 & 0.017 & 689.4735 to 1367.753
\end{tabular}

${ }^{*} P<0.05$.

Coefficient: regression coefficient.

The regression coefficients are the estimated increase in the InOR per unit increase in the covariates. Cons, constant item.

Table 3 | Subsection analysis summary of the allelic genetic model stratified by publication year in the male subgroup.

\begin{tabular}{llccrr}
\hline Subsection & Studies number & Weight (\%) & Pooled OR (95\% Cl) & $\boldsymbol{Z}(\boldsymbol{P})$ & \multicolumn{1}{l}{ (\%) } \\
\hline Subsection 1 & 5 & 77.46 & $1.16(0.95-1.40)$ & 33.8 \\
Subsection 2 & 3 & 22.54 & $0.74(0.31-1.79)$ & $0.66(P=0.14)$ & $74)$ \\
Whole population & 8 & 100.0 & $1.06(0.82-1.36)$ & $0.44(P=0.66)$
\end{tabular}

Subsection 1: published before 2007.

Subsection 2: published after 2009.

the ACE2 G8790A gene polymorphism might not be related to increased risk for $\mathrm{EH}$.

In the meta-regression of the confounding factor, the publication year was considered as the most important heterogeneity source. The publication year before 2007 indicated lower heterogeneity, and suggested that the early studies have the smaller heterogeneity than the latter studies.

The results of the current research conformed to those of Zhou and Yang (2009) who meta-analyzed the ACE2 G8790A gene polymorphism and $\mathrm{EH}$ in a Chinese Han population. The ACE2 G8790A gene polymorphism might not be a genetic risk factor for $\mathrm{EH}$ in the said population. However, not all of the included studies have followed the HWE. For instance, the study of Liu et al. (2005) has deviated from the HWE. Hence, this study was excluded in the current meta-analysis. In addition, three genetic models, namely, allelic, dominant, and recessive genetic models, were adopted in the present study to analyze the research results. In contrast, only the allelic genetic model was used in Zhou's work. Regarding Lu's et al. (2012) work, the limitation also existed. The studies against HWE were also included in the female subgroup in their metaanalysis (Liu et al., 2005; Niu et al., 2007; Si et al., 2009; Zhang et al., 2010). Moreover, another included study was not associated with $\mathrm{EH}$ but orthostatic hypertension (Fan et al., 2009). Given these limitations, Lu's conclusion seemed not credible. 


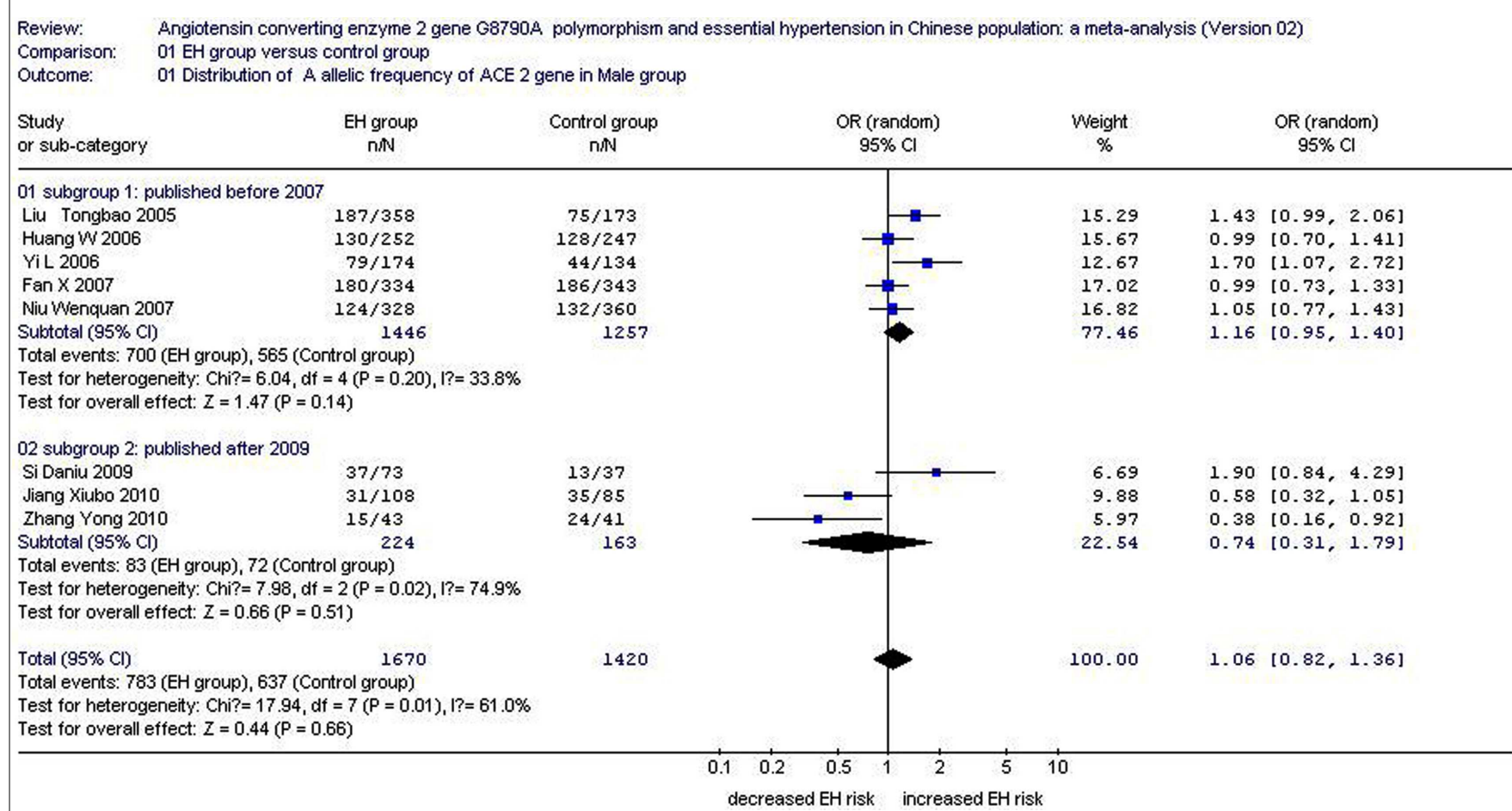

FIGURE 5 | Forest plot of EH associated with ACE2 G8790A gene polymorphism stratified by publication year in male subgroup (distribution of A allelic frequency of $A C E 2$ gene).

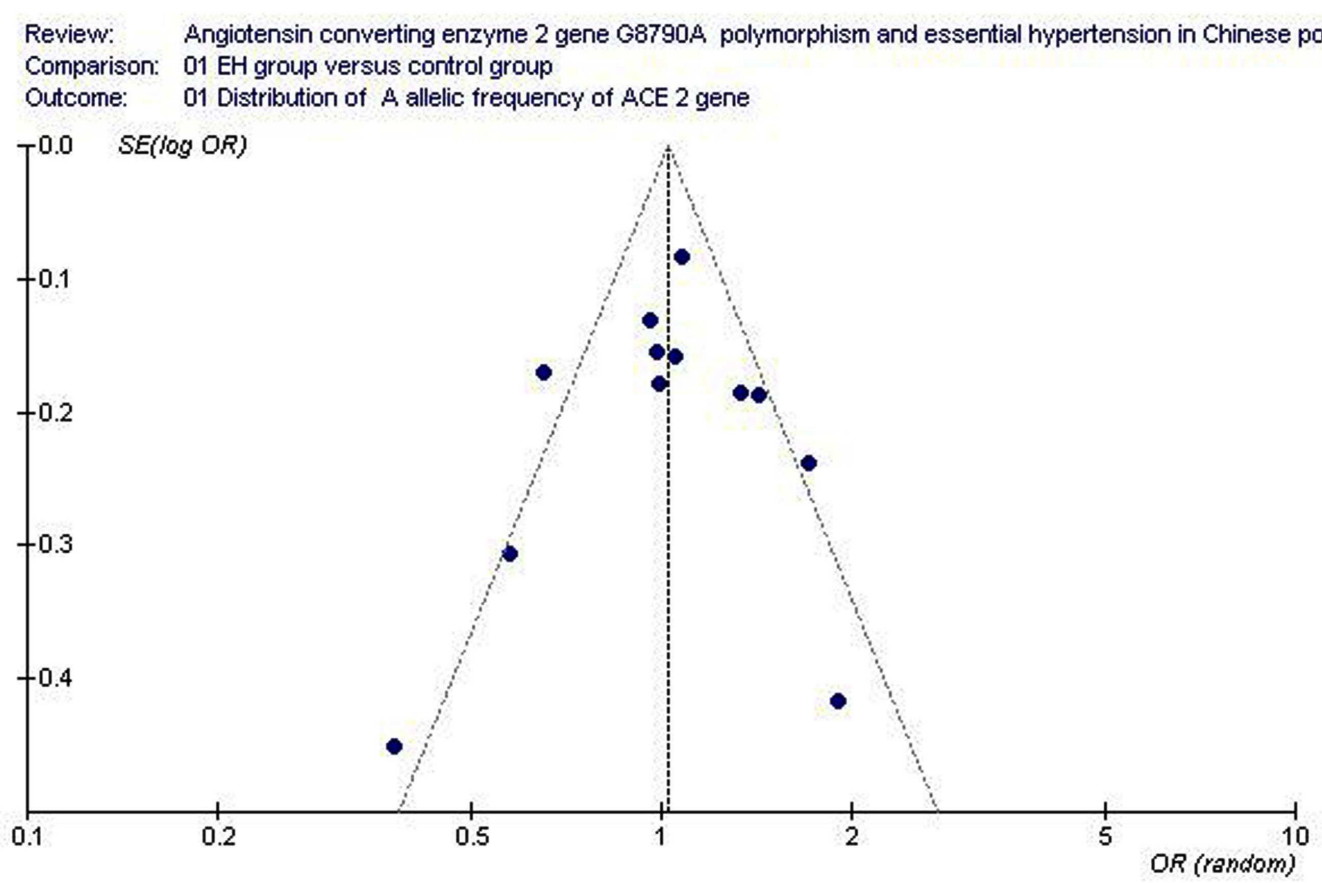

FIGURE 6 | Funnel plot for studies of the association of essential hypertension and ACE2 G8790A gene polymorphism (distribution of A allelic frequency of $\boldsymbol{A C E} 2$ gene). The horizontal and vertical axis correspond to the OR and confidence limits. OR, odds ratio; SE, standard error. 
In conclusion, the current meta-analysis suggested that the ACE2 G8790A gene polymorphism was not associated with susceptibility to EH in the Chinese population. Further studies should use higher investigation sample sizes. Given the relatively small sample size used in the present study, further research should be performed to test the abovementioned conclusion.

\section{ACKNOWLEDGMENTS}

Thank all our colleagues working in the Department of geriatrics, the First Affiliated Hospital of Nanjing Medical University. This work was funded by the National Natural Science Foundation of China (NSFC 81100073 to Dr Yan-yan Li) and the Priority

\section{REFERENCES}

Benjafield, A. V., Wang, W. Y., and Morris, B. J. (2004). No association of angiotensin-converting enzyme 2 gene (ACE2) polymorphisms with essential hypertension. Am. J. Hypertens. 17, 624-628.

Cochran, W. G. (1968). The effectiveness of adjustment by subclassification in removing bias in observational studies. Biometrics 24, 295-313.

Crackower, M. A., Sarao, R., Oudit, G. Y., Yagil, C., Kozieradzki, I., Scanga, S. E., Oliveira-dos-Santos, A. J., da Costa, J., Zhang, L., Pei, Y., Scholey, J., Ferrario, C. M., Manoukian, A. S., Chappell, M. C., Backx, P. H., Yagil, Y., and Penninger, J. M. (2002). Angiotensin-converting enzyme 2 is an essential regulator of heart function. Nature 417, 822-828.

DerSimonian, R., and Laird, N. (1986). Meta-analysis in clinical trials. Control. Clin. Trials 7, 177-188.

Donoghue, M., Hsieh, F., Baronas, E., Godbout, K., Gosselin, M., Stagliano, N., Donovan, M., Woolf, B., Robison, K., Jeyaseelan, R., Breitbart, R. E., and Acton, S. (2000). A novel angiotensin-converting enzyme-related carboxypeptidase (ACE2) converts angiotensin I to angiotensin 1-9. Circ. Res. 87, E1-E9.

Egger, M., Davey Smith, G., Schneider, M., and Minder, C. (1997). Bias in meta-analysis detected by a simple, graphical test. Br. Med. J. 315, 629-634.

Fan, X., Wang, Y., Sun, K., Zhang, W., Yang, X., Wang, S., Zhen, Y., Wang, J., Li, W., Han, Y., Liu, T., Wang, X., Chen, J., Wu, H., and Hui, R. T. (2007). Polymorphisms of ACE2 gene are associated with essential hypertension and antihypertensive effects of Captopril in women. Clin. Pharmacol. Ther. 82, 1-10.
Fan, X. H., Wang, Y. B., Wang, H., Sun, K., Zhang, W. L., Song, X. D., Cheng, J. Z., Wu, H. Y., Zhou, X. L., and Hui, R. T. (2009). Polymorphisms of angiotensin-converting enzyme (ACE) and ACE2 are not associated with orthostatic blood pressure dysregulation in hypertensive patients. Acta Pharmacol. Sin. 30, 1237-1244.

Hang, W., Yang, W., Wang, Y., Zhao, Q., Gu, D., and Chen, R. (2006). Association study of angiotensin-converting enzyme 2 gene (ACE2) polymorphisms and essential hypertension in northern Han Chinese. J. Hum. Hypertens. 20, 968-971.

Jiang, X. B., Zhang, D. F., Jiang, W. J., Wang, S. J., Song, X., Li, D. J., and Jiang, Z. C. (2010). Association of angiotensin-converting enzyme 2 gene G8790A polymorphism with essential hypertension in Han Chinese. Chin. Gen. Prac. 13, 3274-3277.

Kramkowski, K., Mogielnicki, A., and Buczko, W. (2006). The physiological significance of the alternative pathways of angiotensin II production. J. Physiol. Pharmacol. 57, 529-539.

Liu, T. B., Shang, H. P., Zhang, K. X., Zhu, D. L., and Huang, W. (2005). Association of angiotensin I converting enzyme 2 gene polymorphism with essential hypertension in Chinese. Chin. J. Med. Genet. 22, 569-571.

Lu, N., Yang, Y., Wang, Y., Liu, Y., Fu, G., Chen, D., Dai, H., Fan, X., Hui, R., and Zheng, Y. (2012). ACE2 gene polymorphism and essential hypertension: an updated meta-analysis involving 11,051 subjects. Mol. Biol. Rep. 39, 6581-6589.

Mantel, N., and Haenszel, W. (1959). Statistical aspects of the analysis of data from retrospective studies of disease. J. Natl. Cancer Inst. 22, 719-748. Chen, L. H., Zhu, X. L., Zhang, Y.,

Academic Program Development of Jiangsu Higher Education Institutions (PAPD).

\section{SUPPLEMENTARY MATERIAL}

The Supplementary Material for this article can be found online at http://www.frontiersin.org/Vascular_Physiology/10.3389/fphys. 2012.00364/abstract

\section{Table S1 | Characteristics of the investigated studies of the association between the ACE2 G8790A gene polymorphism and EH of the male subgroup.}

\section{Table S2 | RT-PCR primers utilized for each gene in the RT-PCR analysis.}

Niu, W. Q., Qi, Y., Hou, S. Q., Zhou, W. Y., and Qiu, C. C. (2007). Correlation of angiotensin-converting enzyme 2 gene polymorphisms with stage 2 hypertension in Han Chinese. Transl. Res. 150, 374-380.

Ribeiro-Oliveira, A. Jr., Nogueira, A. I., Pereira, R. M., Boas, W. W., Dos Santos, R. A., and Simões e Silva, A. C. (2008). The reninangiotensin system and diabetes: an update. Vasc. Health Risk Manag. 4, 787-803.

Si, D. N., Li, L., and Chui, T. X. (2009). Association of angiotensin I converting enzyme 2 gene polymorphism and essential hypertension with diabetes mellitus. Chin. J. Pract. Nerv. Dis. 12, 38-40.

Tipnis, S. R., Hooper, N. M., Hyde, R., Karran, E., Christie, G., and Turner, A. J. (2000). A human homolog of angiotensin-converting enzyme. Cloning and functional expression as a captopril-insensitive carboxypeptidase. J. Biol. Chem. 275, 33238-33243.

Yi, L., Gu, Y. H., Wang, X. L., An, L. Z., Xie, X. D., Shao, W., Ma, Y., Fang, J. R., An, Y. D., and Zhang, D. L. (2006). Association of ACE, ACE2 and UTS2 polymorphisms with essential hypertension in Han and Dongxiang populations from north-western China. J. Int. Med. Res. 34, 272-283.

Zhang, H. M., Fan, X. H., Han, Y. F., Li, W. J., Yang, X. M., Wang, S. X., Zhou, X. L., Wu, H. Y., and Hui, R. T. (2008). Polymorphism interaction between angiotensin-conversion enzyme 2 gene and angiotensin-conversion enzyme gene on the risk of essential hypertension in women. Chin. Circ. J. 23, 355-359.

Zhang, Y., Wu, K., Jin, S. J., Zhou, D. F., Zhang, Y. X., Chen, S. H., Li, L. J., Wang, Z., Xi, J. L., and Chen, Z. Q.
(2010). Association of angiotensin I converting enzyme 2 gene polymorphism and essential hypertension in Hainan Li Chinese population. Chin. J. Gerontol. 30, 1029-1230.

Zhong, J., Yan, Z., Liu, D., Ni, Y., Zhao, Z., Zhu, S., Tepel, M., and Zhu, Z. (2006). Association of angiotensinconverting enzyme 2 gene $\mathrm{A} / \mathrm{G}$ polymorphism and elevated blood pressure in Chinese patients with metabolic syndrome. J. Lab. Clin. Med. 147, 91-95.

Zhou, J. B., and Yang, J. K. (2009). Metaanalysis of association of ACE2 G8790A polymorphism with Chinese Han essential hypertension. J. Renin Angiotensin Aldosterone Syst. 10, 31-34.

Conflict of Interest Statement: The author declares that the research was conducted in the absence of any commercial or financial relationships that could be construed as a potential conflict of interest.

Received: 22 June 2012; accepted: 24 August 2012; published online: 12 September 2012.

Citation: Li Y-y (2012) Lack of association of ACE2 G8790A gene mutation with essential hypertension in the Chinese population: a meta-analysis involving 5260 subjects. Front. Physio. 3:364. doi: 10.3389/fphys.2012.00364

This article was submitted to Frontiers in Vascular Physiology, a specialty of Frontiers in Physiology.

Copyright (c) $2012 \mathrm{Li}$. This is an openaccess article distributed under the terms of the Creative Commons Attribution License, which permits use, distribution and reproduction in other forums, provided the original authors and source are credited and subject to any copyright notices concerning any third-party graphics etc. 